\title{
Ensino-Aprendizagem Gramatical: Diagnóstico de uma Pesquis(a)ção
}

\author{
Alba Maria PERFEITO \\ Sandra Regina CECILIO ${ }^{1}$ \\ Universidade Estadual de Londrina - UEL
}

Resumo: O objetivo deste artigo é apresentar reflexões acerca de dados provenientes do projeto de pesquisa etnográfica em Lingüística Aplicada "Escrita e ensino gramatical: um novo olhar para um velho problema", desenvolvido pelo Departamento de Letras Vernáculas e Clássicas da Universidade Estadual de Londrina (UEL). Os dados são oriundos da pesquisa-ação de uma professora de Língua Portuguesa de oitava série do ensino fundamental, pertencente à rede pública estadual paranaense. A análise mostra que a professora apresenta certa dificuldade para colocar em prática os pressupostos das novas propostas pedagógicas, mas também aponta para o fato de que discutir e refletir com criticidade sobre a própria prática torna o trabalho mais produtivo, porque a tomada de consciência já é uma ação e parte do processo em direção às mudanças.

Palavras-chave: ensino de língua materna; gramática; reflexão; pesquisa-ação.

\begin{abstract}
The aim of this paper is to present reflections about data of the ethnographical research project in Applied Linguistic "Writing and grammatical teaching: a new look by an old problem", developed by Vernacular and Classical Languages Department of the State University of Londrina (UEL). The data is coming from an action research of a Portuguese teacher taking the eight grade in fundamental level from Paraná public school. Data analysis reveal the searcher teacher found some difficulty in using the new pedagogical proposal, but also point the fact of discussing and reflecting by criticism on own pedagogical
\end{abstract}

\footnotetext{
${ }^{1}$ Doutoranda em Estudos da Linguagem pela Universidade Estadual de Londrina.
} 
practice becomes the work more productive because the conscious awareness is a way in changing direction.

Key words: mother tongue teaching; grammar; reflection; action research.

Resumen: El objetivo de este artículo es de presentear reflexiones acerca de datos provenientes del proyecto de pesquisa etnográfica en Lingüística Aplicada "Escrita y enseñanza gramatical: una nueva mirada para un viejo problema", desarrollado por el Departamento de Letras Vernáculas y Clásicas de la Universidad Estadual de Londrina (UEL). Los datos son oriundos de la pesquisa-acción de una profesora de la Lengua Portuguesa de la octava serie de la enseñanza fundamental, perteneciente a la red pública estadual paranaense. El análisis muestra que la profesora presenta cierta dificultad para poner en práctica los presupuestos de las nuevas propuestas pedagógicas, pero también apunta para el hecho de que discutir y reflejar con criticidad sobre la propia práctica llega a ser el trabajo más productivo porque la toma de conciencia ya es una acción y parte del proceso en dirección a los cambios.

Palabras-clave: enseñanza de la lengua materna; gramática; reflexión; pesquisa-acción.

\section{Considerações Iniciais}

Em trabalho realizado por Neves (1990), verificou-se o pensamento comum, entre professores, de que o objetivo de ensinar Língua Portuguesa é falar e escrever melhor. Conforme a autora, "falar e escrever bem é, acima de tudo, ser bem sucedido na interação" (NEVES, 2000, p. 54). Em Franchi (1991), observamos ser importante, no ensino de língua, oferecer condições aos alunos para operarem conscientemente sobre a linguagem, revendo e transformando os textos, no intuito de perceberem a riqueza das formas lingüísticas disponíveis em suas mais diversas opções. Se as escolhas podem ser conscientes e carregadas de significação, os objetivos pretendidos, com tais escolhas, só serão alcançados caso a interação seja bem sucedida, fato que pode ocorrer de diferentes maneiras, conforme as variadas situações de comunicação. 
Mesmo com a grande discussão acerca do ensino de língua materna de forma integrada, conforme observamos em vários autores como Geraldi (1996, 1997, 1999), Travaglia (2000, 2003), Possenti (1996), Neves (2000, 2002), Antunes (2000) e Mendonça (2001), entre outros, ainda se manifesta, na escola, o peso da tradição gramatical, no preenchimento de estruturas modelares e/ou no uso do texto como pretexto para ensinar gramática, ou mesmo no ensino gramatical teórico-normativo, completamente descontextualizado.

Diante disso, Mendonça (2001) assinala a contribuição dos estudos da Lingüística no contrafluxo da situação, no intuito de integrar, sem artificialidade, no processo pedagógico, as três unidades básicas de ensino de Língua Portuguesa: leitura, produção textual e análise lingüística. A autora afirma que "o trabalho com língua na escola só é possível com o entrelaçamento de diversas atividades" (MENDONÇA, 2001, p. 259), já que a linguagem, assim como o sujeito e suas práticas sociais, é heterogênea. Acrescentamos, aqui, a contribuição da Lingüística Aplicada (doravante LA), em virtude de interessar-se por problemas de uso da linguagem e, em campo mais específico, pelos processos de ensinar e aprender línguas. Dessa maneira, a LA tem muito a oferecer àqueles que se dedicam aos estudos da linguagem no espaço escolar.

Nesse contexto, o projeto de pesquisa etnográfica em LA "Escrita e ensino gramatical: um novo olhar para um velho problema", desenvolvido pelo Departamento de Letras Vernáculas e Clássicas da Universidade Estadual (UEL), objetiva demonstrar que, através da reflexão sobre o trabalho realizado pelos professores-sujeitos envolvidos, é possível aprimorar sua formação profissional e, por conseguinte, o ensino-aprendizagem de língua materna, sobretudo no que diz respeito ao ensino da gramática (ou, mais amplamente, de análise lingüística).

O projeto envolve docentes e alunos de graduação e pósgraduação da Universidade Estadual de Londrina, Universidade Norte do Paraná (Londrina), Universidade do Oeste do Paraná (Cascavel) e professores, com seus alunos de quarta e oitava séries, distribuídos entre escolas públicas e uma particular, nas cidades de Londrina, Maringá, Apucarana e Cascavel. 
Isso posto, assinalamos que o objetivo do artigo em pauta é apresentar reflexões acerca de um recorte de dados proveniente do projeto em foco, no qual apresentaremos excerto de pesquisa voltada para investigar a ação de uma professora de Língua Portuguesa, de oitava série do ensino fundamental, pertencente à rede pública estadual paranaense. ${ }^{2} \mathrm{O}$ estudo é fundamentado na LA e tem como foco o processo de ensinar e aprender Língua Portuguesa, mais especificamente, a análise lingüística.

\section{O Ensino de Língua Portuguesa}

A questão do trabalho com a análise lingüística na escola brasileira tem sido motivo de muita polêmica e discussão. Em Língua Portuguesa (LP), institucionalizou-se um saber metalingüístico "de forma que importa mais saber um determinado discurso a respeito da língua do que se ver produzindo-a e entendendo-a" (SUASSUNA, 1995, p. 123). Um questionamento acentuado a respeito do ensino de LP é se devemos ou não ensinar gramática na escola. No entanto, postulamos: a questão crucial não é ensinar ou não a gramática, mas para quê e como ensiná-la.

Assumindo a concepção de linguagem como interação, em que é vista como espaço de interlocução humana e, portanto, "lugar de constituição de relações sociais, onde os falantes tornam-se sujeitos" (GERALDI, 1999, p. 41), corroboramos a idéia de autores citados de que o ensino de língua materna não pode ser pensado a partir de atividades mecânicas de repetição, de decodificação ou no reconhecimento e preenchimento de estruturas modelares, sejam frasais ou textuais, em virtude de a significação só e constituir-se no processo dialógico-discursivo.

Por tal razão, objetivando alcançar maior êxito no contexto de ensino- aprendizagem, um caminho a ser trilhado é o

\footnotetext{
${ }^{2}$ A referida pesquisa-ação é fruto da pesquisa de Dissertação de Mestrado "Investigando a própria ação: reflexões sobre o ensino da gramática na $8^{a}$ série", realizada entre os anos de 2002 e 2003. Cabe ressaltar que a professorasujeito é também co-autora deste artigo.
} 
trabalho integrado com as práticas de leitura, de produção de textos e de análise lingüística, sem artificialidade. Assim, postulamos a relevância do trabalho pedagógico ser realizado via textos organizados dentro de determinados gêneros discursivos (eixos de progressão curricular).

Nessa perspectiva, vemos o texto como unidade de estudo, por meio do qual se realizam atividades interativas de produção e recepção de sentidos. Em conseqüência, tanto no processo de produção do texto, quanto no de sua recepção, o trabalho de análise lingüística é primordial, visto ser por meio da seleção do(s) gênero(s) discursivo(s) e, conseqüentemente, do "arranjo" composicional; do léxico; das escolhas morfossintáticas, enfim, dos recursos lingüísticoexpressivos veiculados, que se produzem ou co-produzem os efeitos de sentido. Pelas escolhas lingüísticas é possível, também, visualizar a subjetividade, pelo fato de o autor refletir sua individualidade nos enunciados (BAKHTIN, 1997), podendo se revelar, mostrar-se como sujeito.

$\mathrm{Na}$ sociedade, apresentam-se situações discursivas inúmeras, que variam de acordo com as esferas de comunicação. E, assim como há diferentes maneiras de interação comunicativa, os textos resultantes são construídos de diferentes modos. Em vista disso, recorremos à noção bakhtiniana de gêneros do discurso, nos quais os PCN $(1997,1998)$ de Língua Portuguesa estão fundamentados, para explicitar tal diversidade e postular a adoção do texto como unidade de ensino e do gênero como objeto de ensino.

Bakhtin (1997) denomina gêneros do discurso os enunciados relativamente estáveis advindos das diferentes esferas de atividades humanas, que traduzem as condições específicas e as finalidades de cada uma dessas áreas por meio de seu conteúdo temático, seu estilo verbal e sua construção composicional. Para o autor, os inúmeros gêneros existentes em uma sociedade podem ser diferenciados em gêneros primários (simples) e secundários (complexos). Os primários estão relacionados às situações de comunicação verbal espontânea, estabelecendo "relação imediata com a realidade existente e com a realidade alheia" (BAKHTIN, 1997, p. 281), ao passo que os gêneros secundários voltam-se às circunstâncias de comunicação mais complexas e relativamente mais evoluídas, relacionadas, sobretudo, à 
escrita. Entretanto, no processo de formação dos gêneros secundários, os gêneros primários são absorvidos e transmutados, adquirindo uma característica peculiar. Ao veicular os gêneros ao estilo, Bakhtin (1997) ressalta que os enunciados - orais ou escritos - refletem a individualidade do falante ou escritor.

Barbosa (2000), ao discutir os gêneros discursivos, afirma que sua eleição como objeto de ensino de LP pode contemplar o complexo processo de produção e compreensão de textos, em virtude de o conceito incluir aspectos da ordem enunciativo-discursiva. Assinala que, via gêneros discursivos, o professor pode ter parâmetros mais claros acerca do que deve ensinar e avaliar, visto os gêneros nos permitirem circunscrever as formas de dizer, que circulam socialmente. Além disso, na abordagem em tela, são enfatizadas as especificidades de cada gênero, trazendo conteúdos específicos de ensino a ele relacionados (fato "descredenciador" do trabalho com classificações genéricas e tipológicas), o fornecer instrumentos, para que se construam seqüências didáticas e progressões curriculares.

Nos PCN (BRASIL, 1998) de LP, conforme já explicitado, encontramos a defesa do ensino de língua, embasado nos conceitos de gênero discursivo, como objeto de ensino. $\mathrm{O}$ documento postula, fundamentando-se nos estudos de Bakhtin (1997), que os textos veiculados socialmente se configuram dentro de um determinado gênero em função das intenções comunicativas, como parte das condições de produção dos discursos, as quais geram usos sociais que os determinam. Também são organizados de diferentes formas, o que supõe o desenvolvimento de capacidades variadas, as quais devem ser enfocadas nas situações de ensino-aprendizagem. Dessa forma, o trabalho com textos via gêneros do discurso torna-se primordial, por não haver um gênero prototípico, que permita ensinar todos os gêneros em circulação social, pois "os textos se organizam sempre dentro de certas restrições de natureza temática, composicional e estilística, que os caracterizam como pertencentes a este ou àquele gênero" (BRASIL, 1998, p. 23). O documento, conforme visão bakhtiniana, aponta que os gêneros existem em número quase ilimitado, por variarem em função da época, das culturas, das finalidades sociais, de modo que se torna inviável a escola tratar de todos eles. Cabe ressaltar que os PCN (BRASIL, 1998) priorizam os gêneros utilizados em situações públicas 
de uso da linguagem e sugerem uma listagem de gêneros a serem privilegiados nas práticas de leitura e de produção de textos orais e escritos.

Diante do incontável número de gêneros existentes, postulamos a necessidade de serem priorizados gêneros que merecerão abordagem mais aprofundada, de acordo com a necessidade e/ou o nível dos alunos e com os objetivos escolares (formar para a cidadania, preparar o indivíduo para o vestibular, preparar para o trabalho etc). Concordamos com Barbosa (2000) ao referenciar que cada gênero traz em si conteúdos específicos a ele relacionados e que visam a atingir propósitos diferentes, refletindo/refratando suas sócio-histórias de constituição e desenvolvimento. Nessa ótica, uma carta de leitor, uma carta de reclamação, um editorial de jornal, uma resenha crítica, um artigo de opinião, por exemplo, apesar de serem textos pertencentes à ordem do argumentar, são gêneros que possuem diferenças entre si. Cada um se concretiza de uma forma específica, com características próprias, em diferentes situações de produção.

No sentido de ensejar a transposição didática, postulamos a necessidade de uma categorização (não-fechada) dos gêneros discursivos, além daquela listada nos PCN (BRASIL, 1998). Diante disso, recorremos à categorização observada por Dolz e Schneuwly (1996). Na intenção de classificar os gêneros discursivos, os pesquisadores propuseram cinco agrupamentos de gêneros, elaborados com base no domínio social da comunicação a que pertencem, nas capacidades de linguagem envolvidas na produção e compreensão desses gêneros e na construção composicional. $O$ quadro a seguir, disponibilizado por Barbosa (2000), reproduz os agrupamentos propostos pelos autores. Barbosa (2000) lembra que a classificação em pauta possui a vantagem de tematizar o contexto social e histórico e de considerar aspectos relativos à linguagem. Contudo, assinala não ser a única possibilidade para conceber agrupamentos. Ainda, salienta que o importante, em uma classificação de gêneros, é permitir que se possa efetivar uma progressão curricular. 
a) gêneros da ordem do narrar - cujo domínio de comunicação social é o da cultura literária ficcional, enquanto manifestação estética e ideológica que necessita de instrumentos específicos para sua compreensão e apreciação (exemplos destes gêneros seriam: contos de fadas, fábulas, lendas, narrativas de aventura, narrativas de ficção científica, romance policial, crônica literária, etc.). Envolvem a capacidade de mimesis da ação através da criação de uma intriga no domínio do verossímil

b) gêneros da ordem do relatar - cujo domínio de comunicação social é o da memória e o da documentação das experiências humanas vivenciadas (exemplos destes gêneros seriam: relatos de experiência vivida, diários, testemunhos, autobiografia, notícia, reportagem, crônicas jornalísticas, relato histórico, biografia, etc.). Envolvem a capacidade de representação pelo discurso de experiências vividas e situadas no tempo

c) gêneros da ordem do argumentar - cujo domínio de comunicação social é o da discussão de assuntos sociais controversos, visando um entendimento e um posicionamento perante eles (seriam exemplos destes gêneros: textos de opinião, diálogo argumentativo, carta de leitor, carta de reclamação, carta de solicitação, debate regrado, editorial, requerimento, ensaio, resenhas críticas, artigo assinado, etc.). Envolvem as capacidades de sustentar, refutar e negociar posições

d) gêneros da ordem do expor - que veiculam o conhecimento mais sistematizado que é transmitido culturalmente conhecimento científico e afins (exemplos de gêneros: seminário, conferência, verbete de enciclopédia, texto explicativo, tomada de notas, resumos de textos explicativos, resumos de textos expositivos, resenhas, relato de experiência científica, etc.). Envolvem a capacidade de apresentação textual de diferentes formas dos saberes

e) gêneros da ordem do instruir ou do prescrever - que englobariam textos variados de instrução, regras e normas e que pretendem, em diferentes domínios, a prescrição ou a regulação de ações (exemplos de gêneros: receitas, instruções de uso, instruções de montagem, bulas, regulamentos, regimentos, estatutos, constituições, regras de jogos, etc.). Exigem a regulação mútua de comportamentos

91Signum: Estud. Ling., Londrina, n. 8/2, p. 83-107, dez. 20052 A Lingüística Aplicada (LA) 


\section{A Lingüística Aplicada (LA)}

A área de ensino-aprendizagem tem sido alvo de muitas pesquisas no espaço acadêmico. Mais especificamente, em se tratando dos estudos da linguagem, muitos trabalhos estão voltados para o ensino de línguas e, nesse contexto, a LA tem se destacado, devido às valiosas análises e à busca de soluções significativas no desenvolvimento de pesquisas relacionadas ao ensino-aprendizagem.

Celani (2000) afirma ser o campo de atuação da LA extenso, uma vez que seu instrumento de investigação é a linguagem, entendida como articuladora de múltiplos domínios do saber, presente em todos os setores da vida social. Sob tal enfoque, seu objetivo é contribuir com soluções e propostas de encaminhamento para os problemas detectados no cotidiano do uso social da língua.

Nesse sentido, o ponto de partida das pesquisas mais recentes da LA, etnograficamente falando, é fruto de observação direta dos processos interativos de uso da linguagem. As pesquisas de cunho etnográfico ganharam bastante espaço na área, devido ao fato de o pesquisador, como observador participante, investigar, através da análise de dados coletados no ambiente social - por meio de anotações de campo, gravações, escrita de diários etc.-, qual de fato é o problema a ser solucionado, com todas as suas possíveis imbricações. Para, então, intervir em trabalho prático-teórico-prático na parceria com os sujeitos envolvidos, buscando encaminhamentos para resolver o problema detectado.

No contexto educacional, as pesquisas têm como foco o estudo do processo de ensinar e aprender línguas, por meio de observação das ações em sala de aula. Moita Lopes (1996) afirma que esse tipo de pesquisa não se pauta em categorias preestabelecidas, antes de conhecer o contexto de sala de aula, mas a partir de uma questão de pesquisa norteadora do estudo.

$\mathrm{Na}$ área de ensino-aprendizagem, sua contribuição é ampla. Em conseqüência, entendemos que, além da formação docente, outro importante objeto de estudo é o processo de ensinoaprendizagem, fato que justifica sua relação com nosso foco de estudo, ao propormos o trabalho com embasamento metodológico de caráter processual. 


\section{Método}

Conforme apresentado anteriormente, o recorte selecionado para este artigo integra um projeto maior denominado "Escrita e ensino gramatical: um novo olhar para um velho problema", caracterizado como pesquisa etnográfica em LA, desenvolvido pelo Departamento de Letras Vernáculas e Clássicas da Universidade Estadual de Londrina e coordenado pela professora Dr. ${ }^{a}$ Alba Maria Perfeito. O referido projeto encontra-se em andamento e os sujeitos nele envolvidos - professores da universidade e da rede pública e alunos de graduação e pós-graduação - analisam aulas de Língua Portuguesa ministradas para quarta e oitava séries do ensino fundamental, com o objetivo de investigar e intervir, etnograficamente, no trabalho gramatical docente e nas suas relações com as instâncias de leitura e escrita em situações de sala de aula. A escolha das turmas se justifica pelo fato de serem etapas finais dos dois ciclos, componentes do ensino fundamental de primeira a oitava séries.

No recorte que selecionamos, discutimos parte da pesquisa-ação de uma professora de Língua Portuguesa de oitava série do ensino fundamental, pertencente à escola pública estadual paranaense (participante do projeto de pesquisa referenciado e uma das autoras deste artigo). Embasada em Moita Lopes (1996), Celani (2000), André (1998), Kleiman (1999), a pesquisa orienta-se para a sala de aula, como foco do processo de ensinar e aprender Língua Portuguesa, mais especificamente no que tange à análise lingüística. Caracteriza-se como pesquisa de tendência etnográfica e qualitativa, envolvendo investigação diagnóstica e apresentando sugestões de intervenção.

De acordo com Moita Lopes (1996), é muito comum a tendência de pesquisa voltada para a própria ação, na qual o professor é o investigador de sua prática em sala de aula. A tendência é vista como uma maneira privilegiada de gerar conhecimento e avanço educacional. André (1998), ao discutir essa metodologia de pesquisa, reconhece seu valor, no que se refere à melhoria da qualidade de ensino, por levar os participantes a uma reflexão profunda sobre o trabalho docente e uma busca de modificação da própria ação.

Celani (2000) referencia que a educação contínua assume caráter particularmente importante e Kleiman (1999) enfatiza a 
necessidade de redimensionar a formação do professor de língua materna, uma vez que ainda predominam, em cursos de graduação, "uma concepção tecnicista de formação que a equaciona com a apropriação de saberes de diversas áreas, entre elas as de estudos da linguagem" (KLEIMAN, 1999, p. 67). Sob essa ótica, Moita Lopes (1996) ressalta que a formação docente está envolvida com a reflexão crítica sobre o próprio trabalho. Defende, então, um programa de autoformação contínua em que o professor se envolva, refletindo criticamente sobre suas ações.

Isso posto, também entendemos a pesquisa-ação como uma maneira de formação continuada em serviço, pois, à medida que o sujeito investigador reflete, analisa e discute, acerca de suas práticas docentes, vai construindo "uma compreensão mais perspicaz sobre sua sala de aula" (MOITA LOPES, 1996, p. 186) e acumula evidências para a teorização, processo que, segundo o autor, possibilita o desenvolvimento profissional na área da educação.

\section{Análise Reflexiva}

Os dados para a análise em questão foram colhidos nas aulas de Língua Portuguesa, entre os dias 13 e 18 de junho do ano de 2003. Os sujeitos envolvidos configuram 29 alunos de oitava série e a professora de Língua Portuguesa - a própria investigadora, conforme referência a Moita Lopes (1996). A docente é graduada em Letras, efetiva da rede pública estadual do Paraná, ministra aulas de Língua Portuguesa para o ensino fundamental há sete anos e, à época, era mestranda do Programa de Pós-graduação em Estudos da Linguagem, na UEL.

$\mathrm{Na}$ pesquisa, foram gravadas, transcritas e analisadas 20 aulas consecutivas, nas quais os conteúdos enfocados foram as conjunções subordinativas e coordenativas e a abordagem de textos dos gêneros: artigo de opinião, poemas, propaganda publicitária e fábula. No excerto em tela, analisamos as aulas em que a professora abordou o processo de recepção do artigo "A beleza não é um atributo fundamental", do psicanalista Luiz Alberto Py, veiculado na revista Caras, no ano de 1995, e que consta do livro didático adotado pela escola. 
A aula foi iniciada com uma enquete, a fim de que se verificasse e discutisse o pensamento da turma sobre a beleza física e a interior das pessoas. O objetivo foi o de contextualizar, mediando um processo que levasse os alunos a refletirem e externarem suas opiniões a respeito do tema, para somente depois realizarem a leitura do texto. Antes da leitura oral, ainda comentou-se com os alunos que o artigo foi publicado, primeiramente, na revista Caras e, dessa forma, também, os aspectos relativos ao suporte e ao local de circulação do artigo. Convém lembrar que, na maior parte de suas reportagens, a revista trata de fatos relacionados a pessoas de renome na sociedade, como artistas, empresários, cantores, jogadores de futebol etc., quase sempre fotografados com roupas de grife, maquiados, usando jóias, detentores de carros luxuosos, enfim, tentando passar uma imagem de pessoas bonitas e bem sucedidas, ou (talvez) bem sucedidas por serem bonitas.

Após a leitura, professora e alunos discutiram acerca do possível ponto de vista do autor - a beleza física não é o atributo fundamental para alcançar a felicidade amorosa. No primeiro momento de contextualização, os alunos puderam falar sobre seus pontos de vista sobre a questão. Num segundo momento, os discentes fizeram uma interpretação do texto, por escrito, e, a partir disso, houve a discussão de idéias gerais, buscando as marcas de linguagem que produziriam certos sentidos no texto, na tentativa de apreender como o autor construiu e sustentou suas idéias. Nesse sentido, houve a discussão de parágrafo por parágrafo, a fim de explorar os caminhos percorridos por Py na defesa de sua opinião. De acordo com a professora, seu objetivo foi demonstrar que o texto é pertencente ao gênero artigo de opinião e, por esse motivo, é carregado de argumentos, para influenciar e convencer os leitores - principalmente as mulheres de que a beleza física não é essencial para que uma pessoa seja bem sucedida em seus relacionamentos amorosos.

Concordamos com Geraldi (1997) ao postular que a análise lingüística deve ocorrer no interior e a partir das práticas de leitura, bem como nas de produção e refacção textuais dos alunos. Em um trabalho integrado de leitura e de análise lingüística foram propiciados aos alunos momentos de reflexão, nos quais a professora e discentes tentaram co-produzir os sentidos do texto, atentando para os recursos lingüístico-expressivos, agenciados pelo autor, presentes na superfície textual, na seleção do gênero em pauta. 
A docente procurou ensejar a observação de que, a partir do segundo parágrafo, o autor começa a manifestar seu ponto de vista e buscou, na materialidade lingüística do texto, elementos cujos efeitos de sentido seriam relevantes na argumentação exposta pelo autor.

$\mathrm{P}$ - entre muitos mitos... entre os mitos do amor... está o mito da beleza... a beleza influencia no relacionamento amoroso... é isso que ele fala... mas essa não é a opinião dele... aí no segundo parágrafo... começa com que expressão... o segundo parágrafo? A6 - no entanto $\mathrm{P}$ - no entanto... o que significa essa expressão? A2 - quanto mais ( )

$\mathrm{P}$ - tenta trocar essa expressão por uma outra que tenha o mesmo significado... ou uma palavra

A3 - mas

P - mas... (escrevendo no quadro) no entanto é a mesma coisa que mas... porém... contudo... entretanto... e que isso significa? A7 - uma expressão contrária

P - uma expressão contrária... então...o Douglas falou uma expressão contrária... é isso... esse no entanto vai indicar algo contrário... algo contrário a quê? àquilo que já foi dito... então esse no entanto já é uma marca de que o autor não concorda com isso que foi falado no primeiro parágrafo... não é a opinião dele... a beleza influencia no amor... e se nós continuarmos ali óh... "no entanto as coisas não se passam bem assim na realidade"... comprovamos que essa realmente não é a opinião dele... e a partir daqui... a partir do segundo parágrafo... ele começa a defender o ponto de vista dele... de que a beleza não é o fundamental... só essa expressão já é uma marca... é uma prova aqui no texto... é uma marca lingüística... é uma marca textual de que a opinião dele não é esta... ele não comunga com essa idéia aqui de que beleza é fundamental

Pelo exemplo, podemos notar que a docente percorreu o segundo parágrafo, juntamente com os alunos, (embora ocupe espaço bem maior nos turnos de fala), na averiguação das marcas lingüísticas que, na construção dos efeitos de sentidos do texto, podem desvelar o ponto de vista do autor. A primeira marca reveladora de que o autor do texto não adere à opinião geral sobre os mitos do amor e sobre a 
opinião de que a paixão pede a beleza para crescer, é a expressão no entanto no princípio do segundo parágrafo. Apesar de Py já ter mencionado, no início do texto, que os mitos do amor são muito acreditados, mas não são comprovados, é por meio da conjunção adversativa que o leitor pode perceber a diferente opinião do autor daquela explicitada no primeiro parágrafo. Assim, expressões como no entanto, mas, porém, contudo, entretanto servem, genericamente falando, para contestar idéias de outras pessoas ou idéias já ditas ou acreditadas, como, nesse caso, a opinião do autor do texto no que se refere ao ponto de vista "geral".

Outra marca adversativa destacada foi o uso do elemento coesivo porém no quinto parágrafo.

$\mathrm{P}$ - mas o autor diz também que a pessoa bonita tem problemas... com isso... a beleza pode acabar criando problemas para a pessoa bonita... ele fala até aqui no enunciado "porém... em contrapartida"... o que significa esse em contrapartida?

((alguns alunos arriscam))

P- ãh? o que vocês acham que é esse em contrapartida? vai dar uma idéia de que agora?

A7 - o oposto

$\mathrm{P}$ - o oposto.. por um lado... olha aqui óh... por um lado a beleza facilita.... abre portas... em contrapartida ou POR OUTRO LADO... a beleza cria problemas.... que problemas são esses... segundo o autor?

A $2-$ ah... os outros têm inveja

$\mathrm{P}-$ inveja?... mas o autor falou em inveja?

A3 - não

$\mathrm{P}$ - de acordo com a visão do autor primeiro

A2 - que muitas vezes eles... tipo assim... confiam naquela pessoa por ela ser bonita... só que muitas vezes ela não tem capacidade de fazer muita coisa e eles ficam esperando que ela faça muito mas só que ela não tem capacidade... e só... vê a beleza dela... por ela ser bonita... mas às vezes não tem capacidade

( )

$\mathrm{P}$ - na visão do autor... e vocês acham que é só assim? o contrário acontece também? na visão de vocês agora... não acontece... não tem gente que fala assim... ah aquela pessoa é bonita mas deve ser burra... principalmente com a mulheres?

A4 - tem 
P - ou também... é feia... mas pelo menos deve ser inteligente? existem esses comentários também... o autor não falou sobre isso... por que será que o autor não tocou nesse assunto?

$(\quad)$

$\mathrm{P}$ - qual o ponto de vista que ele quer defender?

AA - que a beleza não é fundamental

P - que a beleza NÃO É fundamental... não é um atributo fundamental... então ele tá mostrando que a beleza pode abrir portas mas isso também... por outro lado.. isso também pode criar problemas pra pessoa... vão cobrar demais da pessoa... vão cobrar demais da pessoa bonita... não é?...

Ao discutir com os alunos o uso da adversativa porém, no quinto parágrafo, a professora-sujeito foi em busca dos sentidos que a expressão carrega consigo no contexto. A conjunção, nesse contexto, não criou o efeito de sentido de contestar uma idéia, mas, na leitura realizada, pôde-se inferir que há outros fatos, diferentes dos já mencionados e caracterizados como positivos, que acabam trazendo problemas para a pessoa bonita, como as cobranças demasiadas eventualmente, dirigidas pela sociedade a ela, vendo-a "como a expressão externa de algo interno". O uso do elemento coesivo porém, nesse contexto, encontra-se pleno de outros valores semânticos, diferentemente da marca lingüística no entanto, que inicia o segundo parágrafo. A confirmação parece ser atribuída pelo próprio autor, quando emprega a expressão "faca de dois gumes", indicando que há dois lados diferentes em uma mesma situação. No interior do texto é que o leitor pode detectar os sentidos que a conjunção traz, pois seu uso depende do tipo de estratégia utilizada pelo autor, na construção de seus argumentos, ao defender suas idéias.

Conforme verificamos na fala docente, após enfatizar a opinião do autor foi feito um contraponto, lembrando que o oposto daquilo que o autor tenta afirmar pode acontecer na sociedade, ou seja, as pessoas não darem créditos de competência aos indivíduos dotados de beleza física. Para a ministrante da aula, no texto, o autor não encaminha tal possibilidade de leitura. Isto porque seu objetivo é, certamente, demonstrar que as pessoas belas exteriormente também possuem outros atributos. Aponta, desse modo, que o tipo de beleza em questão não é o fundamental em uma pessoa e que não é 
exclusivamente ela (a beleza) a garantia da felicidade e do sucesso nas diversas instâncias sociais, incluindo aí o relacionamento amoroso. Desse modo, o autor orienta sua fala no sentido de determinadas conclusões, cabendo ao leitor aceitar ou não sua opinião e realizar suas inferências. É importante salientar que o texto foi veiculado em uma revista de tiragem semanal, a qual propicia espaço aos leitores à manifestação de suas opiniões, seja pelo correio convencional ou virtual.

Outra marca lingǘstica, a respeito da qual foi chamada a atenção dos alunos, foi o uso de modalizadores, que deram ao texto certo efeito de distanciamento ou de atenuação do autor, em relação ao seu ponto de vista, em determinados momentos. Embora seja um texto de opinião, o autor o abordou idéias bastante conhecidas. Trabalhando com generalizações, ele incorpora outras vozes ao seu discurso, evitando cair em opiniões estritamente pessoais. As marcas que provocam essa leitura são os modalizadores (podemos, tendemos), representados nas formas verbais utilizadas na primeira pessoa do plural, como: podemos tomar, tendemos a acreditar e, inclusive, o uso de formas verbais com o pronome apassivador se, que delega ao texto sentidos de impessoalidade.

No entanto, as pessoas se revelam pela linguagem, visto que, segundo já posto, ao produzir um discurso a individualidade do sujeito é refletida nos enunciados (BAKHTIN, 1997). Mesmo não assumindo explicitamente as opiniões, o uso do 'nós' pode encaminhar o leitor a entender que são opiniões também do autor, porque as marcas enunciativas presentes na superfície textual sinalizam tal leitura - os próprios modalizadores indicam "o grau de comprometimento do autor com a verdade, ou a justeza da informação, relativizando-a para mais, a certeza absoluta, ou para menos, a possibilidade mais remota" (KLEIMAN, 1997, p. 68).

A professora remete, reflexivamente, os estudantes ao último parágrafo para atentarem como o autor se revela quando, ao fazer uso do advérbio realmente, e assume seu discurso, posicionandose diante dos valores discutidos em todo o texto. $\mathrm{O}$ uso do modalizador em tela é indicador da adesão do autor à tese de que a beleza física não é um atributo fundamental e, ainda, de que sua opinião pessoal foi "explicitada", assinalando que ele considera os valores interiores e atitudes "de amor, carinho e cuidado consigo mesmo" mais valiosos que a beleza natural. 
$\mathrm{P}$ - ao longo de todo o texto o autor ele não se mostra... apesar de ele querer mostrar... defender um ponto de vista... ele não se coloca claramente... ele usa termos e expressões que são assim de todo mundo... ele usa exemplos que as pessoas conhecem... exemplos conhecidos... e assim ele evita cair em opiniões puramente pessoais... mas lá no último parágrafo ele se mostra explicitamente... ele assume uma posição clara... ele mostra a opinião dele... qual é... mostra pra mim uma palavra ou uma expressão... uma parte lá do último parágrafo que prova que o autor está assumindo uma posição... procura uma palavra ou uma expressão que comprova que o autor está dando a opinião dele... está assumindo um ponto de vista

A6 - onde que tá?

$\mathrm{P}$ - no último parágrafo... é no último parágrafo que ele assume A2 - "cada um de nós"

$\mathrm{P}$ - continua... leia esse trecho

A2 - "com isso cada um de nós mostra que mais fundamental do que ser bonito é revelar uma atitude de amor... carinho e cuidado consigo mesmo"

P _ “com isso cada um de nós"... leia essa parte... continue "isso pode"... continua lendo

A2 - "isso pode ser percebido por sinais exteriores que por serem realmente mais valiosos do que a beleza natural acabam se confundindo com ela"

$\mathrm{P}$ - "isso pode ser percebido por sinais exteriores que por serem REALMENTE"... aqui o autor se mostra... aqui ele mostra que essa é a opinião dele... "por serem realmente mais valiosos do que a beleza natural"... quando ele fala que os valores exteriores são realmente mais valiosos ele se mostra... aqui não é a opinião geral... é a opinião dele... se durante todo o texto ele tentou um certo distanciamento aqui ele se mostrou... quando ele diz lá no começo... "diz-se que a paixão pede a beleza para crescer"...isso era... atribuía-se isso... “atribuía-se o conflito à beleza de helena”... quando ele usa essa forma verbal... dessa maneira... ((escrevendo no quadro)) diz-se... atribuía-se

A7 - professora... merece é com c?

((a professora gestualmente responde que sim))

P - quando ele usa essas formas verbais aqui... ele está se colocando? é a opinião dele? é dele?

A3 - não 
P - diz-se... as pessoas disseram... as pessoas atribuíram... ele não se colocou aqui... ele se mostrou impessoal... olha só uma marca do texto... oh Diego... pára de brincar Diego... usando dessa forma cria um efeito de impessoalidade... não é a pessoa do autor que está falando isso mas outras pessoas falaram... quem disse? alguém disse.. ele não está se mostrando... olha uma marca de que ele não está se mostrando... uma outra marca que nós temos no texto... que mostra impessoalidade... mostra o distanciamento do autor é quando ele usa as formas verbais lá no segundo parágrafo "podemos tomar o exemplo do próprio Vinícius de Moraes"... podemos... nós podemos... ele não assumiu isso sozinho... ele colocou... ele aproximou o leitor e ele também cria uma impessoalidade... cria esse distanciamento

Como pudemos verificar pelas descrições realizadas, a docente buscou percorrer leituras juntamente com os estudantes, ressaltando como alguns elementos podem funcionar no texto, construindo sentidos. Todavia, observamos, no excerto anterior, que não houve tempo suficiente para que os alunos fizessem sua caminhada interpretativa, refletindo sobre os questionamentos da professora, a qual se mostrou ansiosa para que a turma acompanhasse seu raciocínio, ao indicar, rapidamente, a leitura da parte do texto comprovadora de sua tese. Fato que, na ocasião, tornou-a pouco mediadora e bastante diretiva.

Pelo discurso da ministrante da aula, detectamos que abordou o texto com a visão reducionista das tipologias - descrição, narração, dissertação, ao comentar com os alunos que "o texto do tipo dissertativo é aquele no qual o autor defende sua tese, tentando influenciar e até modificar a opinião e o comportamento do leitor."

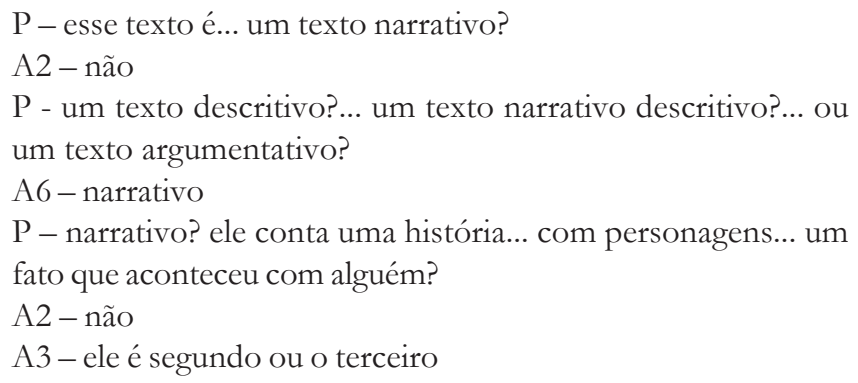


$\mathrm{P}$ - o que é um texto argumentativo?

A3 - tá falando sobre algo

$\mathrm{P}$ - sobre algo... está defendendo um ponto de vista sobre algo...

esse texto tem isso?

A2 - não

$\mathrm{P}$ - tem... olha... o autor nesse texto defende um ponto de vista

e ele mostra isso com exemplos... nesse texto ele tem uma opinião formada sobre o assunto e ele tenta convencer o leitor... tenta convencer o público da revista sobre esse assunto... apesar dele evitar cair na opinião pessoal... ele quer mostrar isso como sendo geral... mas ele tenta convencer

Nesse momento, talvez tivesse sido interessante trabalhar outros artigos de opinião, para que detectassem o que é recorrente nesse gênero, uma vez que não há um texto modelo que "possa 'ensinar' a compreender e a produzir textos pertencentes a todos os tipos existentes" (BARBOSA, 2000, p. 152). O enfoque das aulas poderia ter sido a abordagem do gênero discursivo "artigo de opinião", envolvendo outros textos, primeiramente com o mesmo tema (a influência da beleza física nas interações socais) e, posteriormente, textos que abordassem outros temas, disponibilizados em diferentes suportes, criados por diferentes autores/enunciadores, em outras situações de produção (quem fala, para quem, quando, em que contexto sóciohistórico, com que objetivo e possível intenção, posicionamento ideológico do produtor/enunciador etc.). Tal prática se torna importante no sentido de não priorizar um único agente produtor, principalmente no gênero discursivo em foco, que apresenta discursos marcantemente ideologizados.

Conforme antes mencionado, para Bakhtin (1997), os gêneros discursivos dizem respeito a enunciados mais ou menos estáveis que circulam nas diferentes esferas sociais, dotados de construção composicional, conteúdo temático e estilo verbal. Este último item refere-se às marcas lingüístico- enunciativas do texto de determinado gênero. Dessa maneira, considerando nosso campo específico de análise - a gramática em situações de leitura e escrita -, ao focalizarmos um corpus de textos do mesmo gênero, podemos buscar suas regularidades como as marcas lingüísticas (do gênero) e as enunciativas (do autor). Em artigos de opinião, que abordam a construção de enunciados 
opinativos, o professor pode (e deve) ensejar a observação de como o autor organiza seu texto ao apresentar e sustentar suas idéias, para refutar argumentos e garantir consistência argumentativa ao texto, sempre em relação ao contexto de produção.

Nesse intuito, de acordo com o suporte em que o texto é veiculado e os possíveis interlocutores, o docente, poderá enfocar as marcas lingüísticas do gênero em pauta que são relevantes: a organização do discurso, quase sempre em terceira pessoa; o uso do presente do indicativo - ou do subjuntivo - na apresentação de argumentos e contra-argumentos; a possibilidade de uso do pretérito, em uma explicação ou apresentação de dados; a presença de citações de palavras alheias; a articulação coesiva por operadores argumentativos e o uso de modalizadores de ordem adverbial (na verdade... freqüentemente... realmente) ou verbal (poder... tender...), conforme analisado anteriormente.

Tais marcas, então, viriam inseridas (produzindo efeitos de sentido) no contexto da organização própria do artigo de opinião, considerando os aspectos de apresentação, justificativas/sustentações, refutações, negociações e conclusão (a sustentação final de um ponto de vista). E, no texto em pauta, apareceriam como exemplos de marcas enunciativas (do autor): o uso da primeira pessoa do plural, o arranjo textual; a sofisticada escolha lexical; as citações alheias (a sua concepção de vida/mundo) etc. O que nos faria perguntar: qual seria, de/na verdade, a "gama" de leitores de Caras?

Acreditamos, então, a importância de analisar o recorrente, através da leitura/análise de vários textos de determinado gênero, em termos de se observar como se organizam em determinada área de atividade humana, mas também, as transformações, adaptações sofridas pelo gênero, em certas condições de produção, inclusive as provocadas pelo sujeito-autor.

\section{Considerações Finais}

Pela análise efetivada, pudemos constatar que a docente abordou a gramática em situações de leitura, procurando refletir sobre os possíveis efeitos de sentidos do texto, vinculados aos recursos lingüístico-expressivos, agenciados em sua construção. Todavia, ainda 
percebemos, em seus discurso e ações, o aspecto enraizado das tipologias textuais. Desse modo, evidencia-se certa dificuldade da professora, mesmo com maior embasamento teórico, no processo de transposição didática. Não obstante, o fato de discutir e refletir, com criticidade, a própria prática, buscando saídas, torna seu trabalho mais produtivo, por considerarmos ser a tomada de consciência uma ação e parte do processo, em direção às mudanças. Pensamos, outrossim, que as mudanças levam um certo tempo para ocorrer, tendo em vista a necessidade de o novo ser, interlocutivamente, compreendido, aceito, internalizado e transformado pelo professor, ao evoluir, na árdua caminhada docente.

Diante do exposto, enfatizamos que a alternativa, para o ensino integrado de língua e, nesse sentido, o de análise lingüística, focalizando os gêneros discursivos, configura-se um horizonte de possibilidades de ações pedagógicas mais eficientes do que as voltadas para os "níveis lexicais, oracionais ou mesmo estritamente textuais" (BARBOSA, 2000, p.151). Nessa perspectiva, o cerne do ensino de LP vem a ser os diferentes modos de dizer, determinados por diferentes situações comunicativas, já que os gêneros são formas procedentes de diferentes esferas de comunicação (BAKHTIN, 1997).

\section{Anexo}

\section{A beleza não é um atributo fundamental}

(Luiz Alberto Py)

Entre os mitos do amor - não provados, porém muito acreditados - encontra-se o da beleza. Diz-se que a paixão pede a beleza para crescer e nosso querido poeta Vinícius de Moraes chegou ao extremo de afirmar: "As feias que me perdoem, mas beleza é fundamental”. Já na descrição homérica da guerra de Tróia, atribuía-se o conflito à beleza de Helena, reforçando a crença no poder da estética e em sua importância para o florescimento do amor.

No entanto, as coisas não se passam bem assim na realidade. Se a beleza fosse imprescindível para o amor, onde ficariam todos os feios e as feias que conhecemos, provavelmente a maior parte da população? Eles precisariam perguntar ao poeta para que 
seria a beleza fundamental. Como a beleza é menos freqüente do que a feiúra, podemos presumir que a maioria formada pelos feios dê valor à qualidade que lhes é ausente e, por essa razão, haveria uma ponderável parcela de pessoas valorizando, até excessivamente, a beleza como qualidade importante na busca de um parceiro. Para confirmar essa hipótese, podemos tomar o exemplo do próprio Vinícius de Moraes, que certamente já não primava pela beleza na época em que criou a famosa frase.

Freqüentemente, vemos casais que nos chamam a atenção exatamente por serem singularmente díspares, pois, enquanto um é muito bonito, o outro é bem o contrário. É provável que isso se deva a um fenômeno bastante comum - a atração dos opostos. Tanto quanto uma pessoa feia pode valorizar a beleza como qualidade que busca em seu parceiro, a pessoa bonita pode se desinteressar por uma qualidade que, para ela, não passa de um dom natural, em geral escassamente apreciado por não ser fruto de um especial esforço, por não ser uma conquista, mas algo recebido, por assim dizer, de mão beijada.

$\mathrm{Na}$ verdade, se pensarmos friamente, a beleza - como característica desejada no parceiro que buscamos - deve vir numa posição não muito destacada, visto que existem muitas outras qualidades que são de fato mais fundamentais quando procuramos nosso companheiro de viagem pela vida. Honestidade, inteligência, capacidade de amar, diligência, generosidade, bondade, disciplina pessoal e saúde são algumas das qualidades que valorizam uma pessoa mais que simplesmente sua formosura. Daí a sabedoria popular afirmar que "beleza não põe mesa".

Não resta a menor dúvida de que a beleza abre as portas, facilita um primeiro contato, cria uma impressão favorável e uma predisposição positiva nas pessoas. Até porque ela tende a ser vista como a expressão externa de algo interno, ou seja, mostra-se como uma prévia de qualidade a serem percebidas posteriormente. Tendemos a acreditar que uma pessoa é boa e inteligente simplesmente porque é bela. Isso, porém, pode se tornar uma faca de dois gumes na medida em que se passa a esperar um melhor desempenho e um maior leque de qualidades em uma pessoa, apenas pelo fato de ela ser bonita. 
É muito comum encontrarmos entre as mulheres - como corolário do mito da beleza fundamental - um outro mito: o da capa de revista. Muitas mulheres tendem a ficar inseguras quando disputam um namorado com outra que consideram mais bonita ou quando percebem seu homem manifestar interesse por uma mulher do tipo "capa de revista". Na imaginação, acolhem a idéia de que os homens tenderiam a procurar mulheres especialmente bonitas para serem suas parceiras, o que viria a se encaixar com a idéia de que a beleza seria mesmo a qualidade mais valorizada por eles. Podem até existir aqueles que colocam a beleza em primeiro lugar, mas é muito provável que sejam minoria. A maior parte dos homens está em busca de mulheres com outras qualidades consideradas mais fundamentais.

A qualidade de fato mais importante está na capacidade de cada indivíduo tirar partido dos aspectos positivos de sua aparência. Com isso, cada um de nós mostra que, mais fundamental do que ser bonito, é revelar uma atitude de amor, carinho e cuidado consigo mesmo. Isso pode ser percebido por sinais exteriores que, por serem realmente mais valiosos do que a beleza natural, acabam se confundindo com ela. O que acontece, muitas vezes, é que uma pessoa se torna atraente e nos parece bonita devido somente às suas outras qualidades.

(Revista Caras, 02/3/95)

\section{Referências Bibliográficas}

ANDRÉ, Marli Eliza Dalmazo Afonso de. Etnografia da prática escolar. 2. ed. Campinas: Papirus, 1998.

ANTUNES, Irandé Costa. A análise de textos na sala de aula: elementos e aplicações. In: MOURA, Denilda. (Org). Língua e ensino: dimensões heterogêneas. Maceió: EDUFAL, 2000. p. 13-20.

BAKHTIN, Mikhail. Estética da criação verbal. Trad. Maria E. Galvão G. Pereira. 2. ed. São Paulo: Martins Fontes, 1997.

BARBOSA, Jacqueline Peixoto. Do professor suposto pelos PCNs ao professor real de língua portuguesa: são os PCNs praticáveis? In: ROJO, Roxane. (Org.) A prática de linguagem em sala de aula. Praticando os PCNs. São Paulo: EDUC/Campinas: Mercado de Letras, 2000. p. 149-182. 
BRASIL. Parâmetros Curriculares Nacionais. Língua Portuguesa: terceiro e quarto ciclos. Brasília: MEC/SEF, 1998.

Parâmetros Curriculares Nacionais. Língua Portuguesa: primeiro e segundo ciclos. Brasília: MEC/SEF, 1997.

CECILIO, Sandra Regina. Investigando a própria ação: reflexões sobre o ensino da gramática na 8 a série. 2004. Dissertação (Mestrado em Estudos da Linguagem) - Universidade Estadual de Londrina, Londrina.

CELANI, Maria Antonieta Alba. A Relevância da Lingüística Aplicada na Formulação de uma Política Educacional Brasileira. In: FORTKAMP, Mailce Borges Mota; TOMITCH, Lêda Maria Braga (Orgs.) Aspectos da Lingüística Aplicada; estudos em homenagem ao Professor Hilário Inácio Bohn. Florianópolis: Insular, 2000. p.17-32.

DOLZ, Joaquim; SCHNEUWLY, Bernard. Genres et progression en expression orale et écrite: elémentes de refléxion à propos d'une experience romande. Enjeux, Genebra (Suíça), p .31-39, 1996. Trad. de Roxane Rojo. (mimeo).

FRANCHI, Carlos. Criatividade e gramática. São Paulo: SE/CENP, 1991.

GERALDI, João Wanderley. O texto na sala de aula. 2. ed. São Paulo: Ática, 1999.

Portos de passagem. 4. ed. São Paulo: Martins Fontes, 1997.

. Linguagem e Ensino - exercícios de militância e divulgação. Campinas: Mercado de Letras/Associação de Leitura do Brasil, 1996.

KLEIMAN, Angela Del Carmen Bustos Romero de. Concepções da escrita na escola e formação do professor. In: VALENTE, André (Org.). Aulas de Português: perspectivas inovadoras. Petrópolis: Vozes, 1999. p. 67-80.

Pontes, 1997.

Texto e leitor: aspectos cognitivos da leitura. 5. ed. Campinas: 
MENDONÇA, Marina Célia. Língua e Ensino: políticas de fechamento. In: MUSSALIM,Fernanda; BENTES, Ana Christina (Orgs). Introdução à Lingüística: domínios e fronteiras. São Paulo: Cortez, 2001. p. 233-264. v. 2.

MOITA LOPES, Luiz Paulo da. Oficina de lingüística aplicada. A natureza social e educacional dos processos de ensino-aprendizagem de línguas. Campinas: Mercado de Letras, 1996.

NEVES, Maria Helena de Moura. A Gramática: história, teoria e análise, ensino. São Paulo: Editora da Unesp, 2002.

A gramática: conhecimento e ensino. In: AZEREDO, José Carlos de. Língua Portuguesa em debate: conhecimento e ensino. Petrópolis: Vozes, 2000, p. 52-73.

Gramática na escola. São Paulo: Contexto, 1990. (Série Repensando a Língua Portuguesa)

POSSENTI, Sírio. Por que (não) ensinar gramática na escola. Campinas: Mercado de Letras/Associação de Leitura do Brasil, 1996.

SUASSUNA, Lívia. Ensino de língua portuguesa - uma abordagem pragmática. Campinas: Papirus, 1995.

TRAVAGLIA, Luiz Carlos. Gramática ensino plural. São Paulo: Cortez, 2003.

Gramática e interação: uma proposta para o ensino de gramática no $1^{\circ}$ e $2^{\circ}$ graus. 5. ed. São Paulo: Cortez, 2000. 